\title{
Synthesis, Textural and Structural Properties of Calcium Hydroxide Nanoparticles in Hydro-Alcoholic Suspension
}

\author{
Giuliana Taglieri'1, Claudia Mondelli², Valeria Daniele1, Emanuela Pusceddu ${ }^{3}$, \\ Giancarlo Scoccia ${ }^{1}$ \\ ${ }^{1}$ Department of Industrial and Information Engineering and Economics, University of L'Aquila, L'Aquila, Italy \\ ${ }^{2}$ CNR-IOM-OGG Institut Laue Langevin, Grenoble, France \\ ${ }^{3}$ Institute of Biometeorology, National Research Council, Firenze, Italy \\ Email: giuliana.taglieri@univaq.it, mondelli@ill.fr, valeria.daniele@univaq.it, emanuela.pusceddu@gmail.com \\ giancarlo.scoccia@univaq.it
}

Received 9 February 2014; revised 11 March 2014; accepted 20 March 2014

Copyright (C) 2014 by authors and Scientific Research Publishing Inc.

This work is licensed under the Creative Commons Attribution International License (CC BY).

http://creativecommons.org/licenses/by/4.0/

(c) (i) Open Access

\begin{abstract}
The use of calcium hydroxide nanoparticles (nanolime) in hydro-alcoholic suspensions represents a good enhancement in particular in the conservation of stones and surfaces of interest in Cultural Heritage. In this work we have produced nanolime by using our alternative method of synthesis (based on the use of a surfactant agent in the original solution) and we have studied, for the first time, structural and morphological properties of the synthesized nanoparticles directly in hydroalcoholic suspension by synchrotron $\mathrm{X}$-ray diffraction technique and transmission electron microscope observations. The particles characterization was performed on suspensions synthesized by varying surfactant content in the synthesis procedure and the water/alcohol ratio, too. We have found that only pure and crystalline $\mathrm{Ca}(\mathrm{OH})_{2}$ particles produced during the synthesis procedure and they maintained stably in suspension. These particles were hexagonally plated and regularly shaped with side dimension ranging from 300 to $40 \mathrm{~nm}$ or less; they had a platy habit and they presented, particularly with high alcohol content in suspension, a preferred orientation along z-axis.
\end{abstract}

\section{Keywords}

Nanostructures; Chemical Synthesis; X-Ray Diffraction; Crystal Structure 


\section{Introduction}

Calcium hydroxide was a material with numerous chemical, industrial, environmental, and architectural applications [1]-[8]. In all its applications, a high reactivity was of paramount importance, so that $\mathrm{Ca}(\mathrm{OH})_{2} \mathrm{particles}$ with submicrometric dimensions (nanolime) were recently introduced in the field of Cultural Heritage conservation in order to obviate to the limitation of traditional treatments. The produced nanolimes were successfully employed in form of hydro-alcoholic suspension on mural paintings, stuccoes and frescoes [9] as well paper and wood deacidification [10]; refurbishments of architectonical surfaces were considered too [11]-[14]. Nanoparticles of calcium hydroxide offered, in addition to compatibility and sustainable action towards the main historical substrates, the following advantages: the possibility to penetrate deep into damaged zones, less limitations due to the particle size, high reactivity and fast reactions, such as carbonatation, in the treated zones, high purity and defined composition [15] [16].

Nanolime was typically synthesized by a chemical precipitation process in supersaturated aqueous solutions of reactants; in particular, the method started from aqueous sodium hydroxide solution $(\mathrm{NaOH})$ added drop by drop in an aqueous calcium chloride $\left(\mathrm{CaCl}_{2}\right)$ solution, maintained at high temperature. The supersaturation degree, the high temperature and the slow mixing time tended to favor $\mathrm{Ca}(\mathrm{OH})_{2}$ nucleation rate with respect to particle growth, promoting the precipitation of nanosized calcium hydroxide particles. After synthesis, the produced white precipitate phase was washed, in order to remove the sodium chloride that was produced during the reaction, and water was partially substituted with an alcoholic medium to improve particles disagglomeration and stability ([17] and ref. in). Disagglomeration allowed to have higher specific surface, leading to more reactive and more penetrating particles; besides, the higher stability of $\mathrm{Ca}(\mathrm{OH})_{2}$ alcoholic suspensions in comparison to aqueous media, reduced the tendency to form a white film onto the surfaces to be consolidated [18].

In the present work we proposed, for the first time, the study of the crystal structure of calcium hydroxide nanoparticles directly in hydro-alcoholic suspension. The nanoparticles were synthesized by an original method that allows obtaining them easily and drastically reducing the time of synthesis with respect to other procedures reported in literature [19]-[21]. In fact, especially if tenths of grams were prepared, we passed from several hours for the drop by drop method to few minutes, as discussed in our previous work [22]; this ratio scales with the quantity of the preparation. The straightforwardness and quickness of our synthesis method could allow to scale-up the nanolime production opening different possibilities in engineering fields, where the use of lime play a fundamental role [22] [23].

In this paper we compared an aqueous nanolime suspension synthesized drop by drop (method 1), to the nanolime obtained by our original method (method 2). Actually, in method 2) a non-ionic surfactant agent was added in the initial aqueous solutions of the reactants, allowing us to obtain, in very simple and more effective way, the final product mixing the starting solutions simultaneously. We considered different surfactant contents and different water/2-propanol ratios, in order to examine their influence on the structural parameters of calcium hydroxide. For both methods, we carried out a partially substitution of the initial dispersing medium (water) with 2-propanol, leaving a water residual content of 75\%, 50\% and $25 \%$ in volume, respectively.

In spite of several scientific works done in last years to characterize the final dried phase of the nanolimes, to our knowledge nobody has studied the structure of $\mathrm{Ca}(\mathrm{OH})_{2}$ nanoparticles directly in suspension, as they are used in the applications. We studied the structure of the $\mathrm{Ca}(\mathrm{OH})_{2}$ nanoparticles in suspension by means of diffraction from X-ray synchrotron radiation at the European Synchrotron Radiation Facility (ESRF) in Grenoble (France). The high energy and high flux of this source have allowed measurements of diffraction in transmission of the particles inside the hydro-alcoholic medium. Data were analyzed by means of the Rietveld method and we investigated the structure of $\mathrm{Ca}(\mathrm{OH})_{2}$ particles in suspension in terms of cell parameters, atomic coordinates, bond lengths and angles; we determined morphology and preferred crystallographic orientation too. March model [24] was widely used in Rietveld refinements for correcting the diffraction intensities with respect to the effects of preferred orientation.

The morphology and particles size were also investigated by transmission electron microscopy (TEM).

\section{Materials and Methods}

\subsection{Synthesis of $\mathrm{Ca}(\mathrm{OH})_{2}$ Nanoparticles}

Calcium chloride dihydrate $\left(\mathrm{CaCl}_{2} \cdot 2 \mathrm{H}_{2} \mathrm{O}\right)$, sodium hydroxide $(\mathrm{NaOH})$ and 2-propanol pro analysi products, supplied by Merck, were used without further purification. In case of synthesis method 2) polyoxyethylene (10) 
tertoctylphenyl ether, Triton X-100 $\left(\mathrm{C}_{14} \mathrm{H}_{22} \mathrm{O}\left(\mathrm{C}_{2} \mathrm{H}_{4} \mathrm{O}\right)_{10}\right)$, a high-purity, water-soluble, liquid, non-ionic surfactant, purchased from Fluka were used too. Water was purified by a Millipore Organex system $(\mathrm{R} \geq 18 \mathrm{M} \Omega \mathrm{cm})$.

Method of synthesis 1$)$. This method started from two aqueous solution of calcium chloride $(0.3 \mathrm{M})$ and sodium hydroxide $(0.6 \mathrm{M})$ maintained at the temperature of about $90^{\circ} \mathrm{C}$; the alkaline solution of $\mathrm{NaOH}$ was added "drop by drop" to the $\mathrm{CaCl}_{2}$ one, as reported in our previous work [25]. Aqueous nanolime suspension (with a $\mathrm{Ca}(\mathrm{OH})_{2}$ concentration of $10 \mathrm{mg} / \mathrm{ml}$ ) has been defined as sample $\mathbf{1}$.

Method of synthesis 2). In the original solution of $\mathrm{CaCl}_{2}$ and $\mathrm{NaOH}$ a surfactant agent (Triton X-100) was added and then the solutions were mixed together simultaneously, at the temperature of $90^{\circ} \mathrm{C}$ [25]. A suspension characterized by a $\mathrm{Ca}(\mathrm{OH})_{2}$ concentration of $10 \mathrm{mg} / \mathrm{ml}$ was obtained. In particular, following this procedure, we prepared two $\mathrm{Ca}(\mathrm{OH})_{2}$ suspensions, each characterized by a surfactant content equal to $(0.40 \pm 0.02) \mathrm{g}$ and (4.00 $\pm 0.02) \mathrm{g}$ respectively. As in method 1 ), we performed several deionised water washings to remove the $\mathrm{NaCl}$ produced and the surfactant too, obtaining two final suspensions called 2I and 2II samples, respectively.

For both methods, we carried out a partially substitution of the initial dispersing medium (water) with 2-propanol, leaving a water residual content of: $75 \%$ in volume (samples $\mathbf{1}_{\mathbf{7 5}}, \mathbf{2}_{\mathbf{7 5}}$ and $\mathbf{2} \mathbf{I I}_{\mathbf{7 5}}$ ), $50 \%$ in volume (sample $\mathbf{2} \mathbf{I I}_{50}$ ) and $25 \%$ in volume (samples $2 \mathbf{I}_{25}$ and $\mathbf{2} \mathbf{I I}_{25}$ ).

\subsection{Characterization of the $\mathrm{Ca}(\mathrm{OH})_{2}$ Nanoparticles}

We investigated, by TEM technique (Philips CM100), the dried particles morphology of the samples under study. The measurements were performed on the samples dried under vacuum.

We performed the SR-X ray measurements on GILDA (BM08) beamline at ESRF; the patterns were collected in Debye-Scherrer geometry on a 2D image plate detector. The experiment was performed at an incident beam wavelength of $\lambda=0.7277 \AA$ and the sample-to-detector distance adjusted to obtain data within the $6^{\circ}-53^{\circ} 2 \theta$ angle range. Data were collected from $0.2 \mathrm{ml}$ of hydro-alcoholic suspension sealed within a cell with Kapton windows, mounted on a rotating sample holder in order to avoid deposition of the nanoparticles during the measurement, to make a good average of the structural characteristics of the particles in suspension and to improve statistics. Patterns of each of the three solvents, water, 2-propanol and Triton X-100 were collected to consider their contribution in the analysis of the background in the hydro-alcoholic $\mathrm{Ca}(\mathrm{OH})_{2}$ suspensions data. Sampleto-detector distance, detector-tilt angles were calibrated against standard $\mathrm{SiO}_{2}$ measured in the same geometry of the samples. Diffraction images were integrated into $2 \theta$ patterns with the program Fit2D [26]. Each pattern was analyzed by the Rietveld method implemented in the FullProf package [27]. Structural refinements of $\mathrm{Ca}(\mathrm{OH})_{2}$ were performed considering the P-3m1 space group and taking data from Ref. [28] as initial values. We refined the zero point, scale factor, cell parameters, atomic coordinates, bond lengths and angles, Debye Waller factors and preferred orientation parameters. We introduced preferred orientation in order to correct a lack of intensity on some reflections. We used March model for preferred orientation as implemented in Fullprof program:

$$
P_{h}=G_{2}+\left(1-G_{2}\right)\left[\left(G_{1} \cos \alpha\right)^{2}+\frac{\sin \alpha_{h}}{G_{1}}\right]^{-3 / 2}
$$

where $G_{1}$ and $G_{2}$ were parameters, which could be refined and $P_{h}$ is the angle between the scattering vector and the normal to the crystallites (platy habit) or to the fibber axis direction. When $G_{1}>1$, particles were characterized by a "platy habit" if, as here, Debye-Scherrer geometry was used [29].

By Rietveld analysis we also determined the coherent domain size for each considered sample. In particular, the average apparent size was calculated using the different reciprocal lattice vectors as reported in Fullprof manual [27].

\section{Results and Discussions}

\subsection{Morphology of the $\mathrm{Ca}(\mathrm{OH})_{2}$ Nanoparticles}

We reported, in Figure 1, TEM observations on sample 1: particles were hexagonally plated and regularly shaped, with side dimensions ranging from $400 \mathrm{~nm}$ to about $100 \mathrm{~nm}$, having the typical habit of crystalline $\mathrm{Ca}(\mathrm{OH})_{2}$ and so thin to be transparent to the electron beam (Figure 1(b)). Besides, we noted that $\mathrm{Ca}(\mathrm{OH})_{2}$ particles were placed one upon another in both images.

In Figure 2 we reported TEM images referred to 2I sample. Also for this sample, the particles appeared hex- 


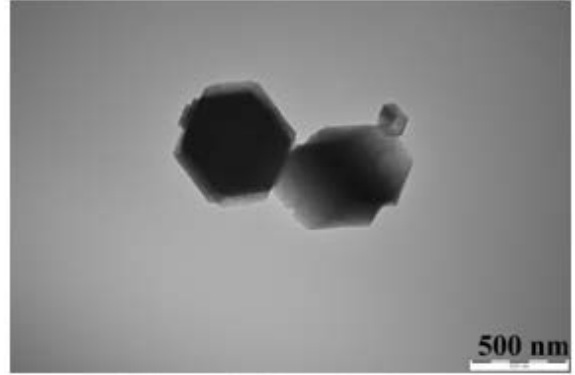

(a)

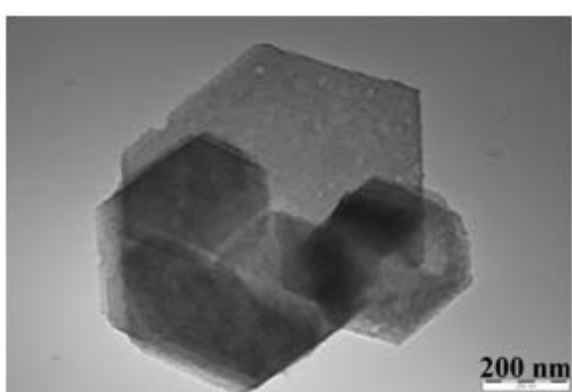

(b)

Figure 1. TEM images on sample 1: (a) particles placed one upon another, with side dimensions up to $100 \mathrm{~nm}$; (b) group of hexagonal particles with side dimension ranging from $200 \mathrm{~nm}$ to $400 \mathrm{~nm}$ [25].

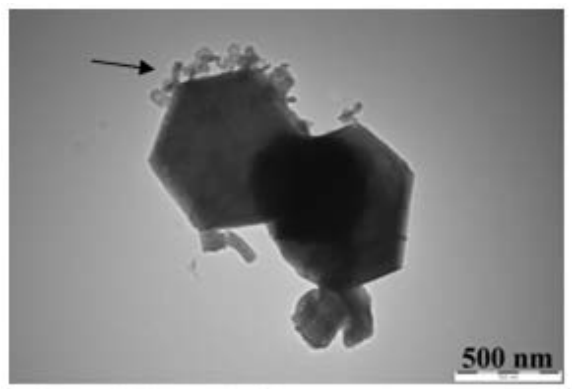

(a)

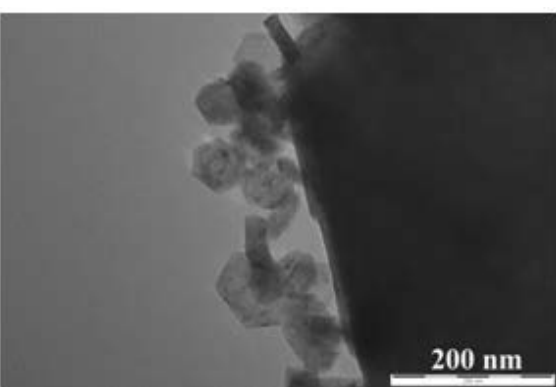

(b)

Figure 2. TEM micrographs on 2I sample: (a) hexagonal particles with side dimension of about 300 $\mathrm{nm}$ and a group of smaller particles marked by arrow; (b) higher magnification showing that the smaller particles are hexagonally shaped and with side dimensions $\leq 40 \mathrm{~nm}$.

agonally plated and regularly shaped, with side dimension ranging from $300 \mathrm{~nm}$ to $40 \mathrm{~nm}$ or less, as shown in Figure 2(b)).

TEM micrographs referred to 2II sample were reported in Figure 3. We found particles with side dimensions generally ranging from $300 \mathrm{~nm}$ to $20 \mathrm{~nm}$ or less and generally not placed one upon another (Figures 3(a)-(c)). In particular, it was remarkable the presence of linear chains visible in all images and better showed in Figure 3(d)); these chains were however constituted by very small particles characterized by diameters less than $10 \mathrm{~nm}$. The presence of very small particles could be related to the higher amounts of surfactant that favored the reduction of the particles size.

These results clearly showed that the use of the surfactant improved the ability to synthesize smaller particles. Moreover, from TEM observations, either in sample 2I and in 2II, Ca(OH $)_{2}$ particles did not appear placed one upon another (as instead it happened in sample 1) showing how the surfactant contributed to prevent nanoparticles agglomeration in suspension, as supported by literature ([30] and ref. in).

\subsection{Structural Properties of the Particle in Hydro-Alcoholic Suspension}

From the analysis of the SR-X ray experimental data we determined the structural parameters of the $\mathrm{Ca}(\mathrm{OH})_{2}$ crystals in suspensions synthesized by the two different methods: cell parameters, atomic coordinates, interatomic distances and bond angles, Debye-Waller factors, preferred orientation of crystallites and average grain dimension. We used the pseudo-Voigt profile function of Thompson, Cox and Hastings [31] in order to fit the peak shapes. The instrumental contribution to peak broadening was determined measuring a diffraction pattern of a $\mathrm{LaB}_{6}$ sample in the same geometry of the samples [32].

In Figure 4 we reported as an example the SR-X ray diffraction pattern for sample $\mathbf{2} \mathbf{I}_{25}$, refined with Rietveld method [33]. The quality of the refinement could be appreciated from the spectra-difference, in blue, between the measured spectra, in red, and the calculated spectra, in black; the green lines indicate the Bragg reflections. The large background comes from the solvents that give large shaped peaks relative to the amorphous liquid. This background was refined and did not affect our analysis. 
In all our samples only the $\mathrm{Ca}(\mathrm{OH})_{2}$ crystalline phase was stably present in suspension, with the main Bragg reflection attributed to (101) peak $\left(\mathrm{d}_{101}=1.33 \AA\right)$ and it could be described in the space group P-3 ml. We reported in Table 1 the structural results, taking into account the comparison between samples synthesized without and with the addition of the surfactant (samples $\mathbf{1}, \mathbf{2 I}$ and 2II, respectively).

The structure parameters of $\mathrm{Ca}(\mathrm{OH})_{2}$ particles in suspension as a function of the ratio water/alcohol were presented in Table 2, for $\mathbf{2 I}$ and 2II series; the Ca-O and O-H distances and bond angles were reported too.

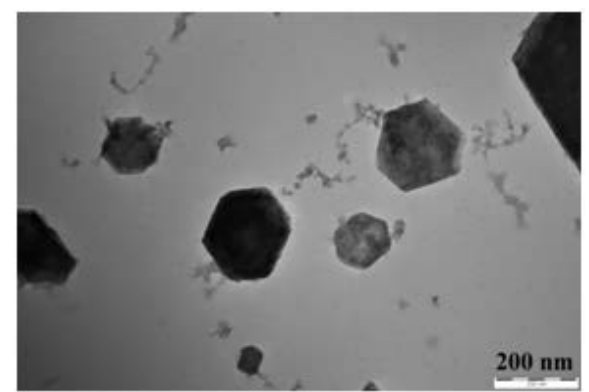

(a)

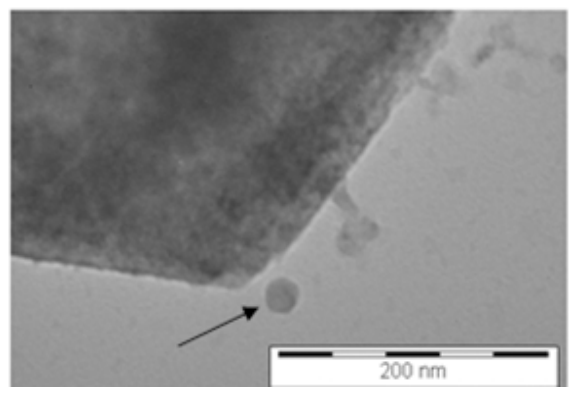

(c)

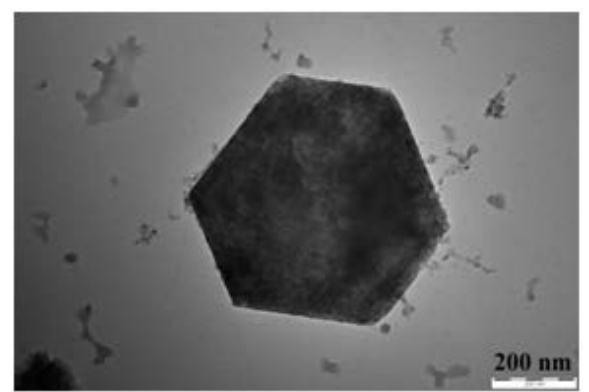

(b)

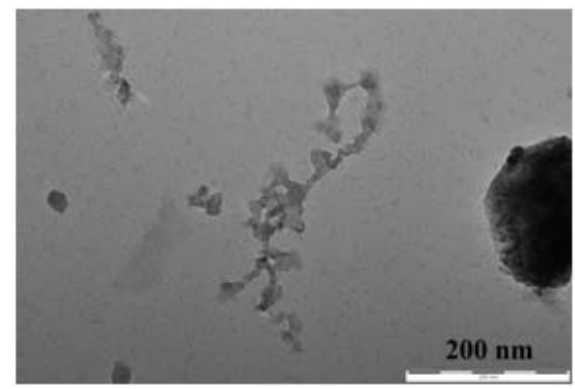

(d)

Figure 3. TEM micrographs on 2II sample: (a)-(b) the hexagonal particles had side dimension ranging from $300 \mathrm{~nm}$ to about $50 \mathrm{~nm}$; (c) zoom view of image (b) outlining that the particle, marked by black arrow, had side dimension less than $20 \mathrm{~nm}$; (d) a linear chains in the suspension composed by very small particles (diameter $<10 \mathrm{~nm}$ ).

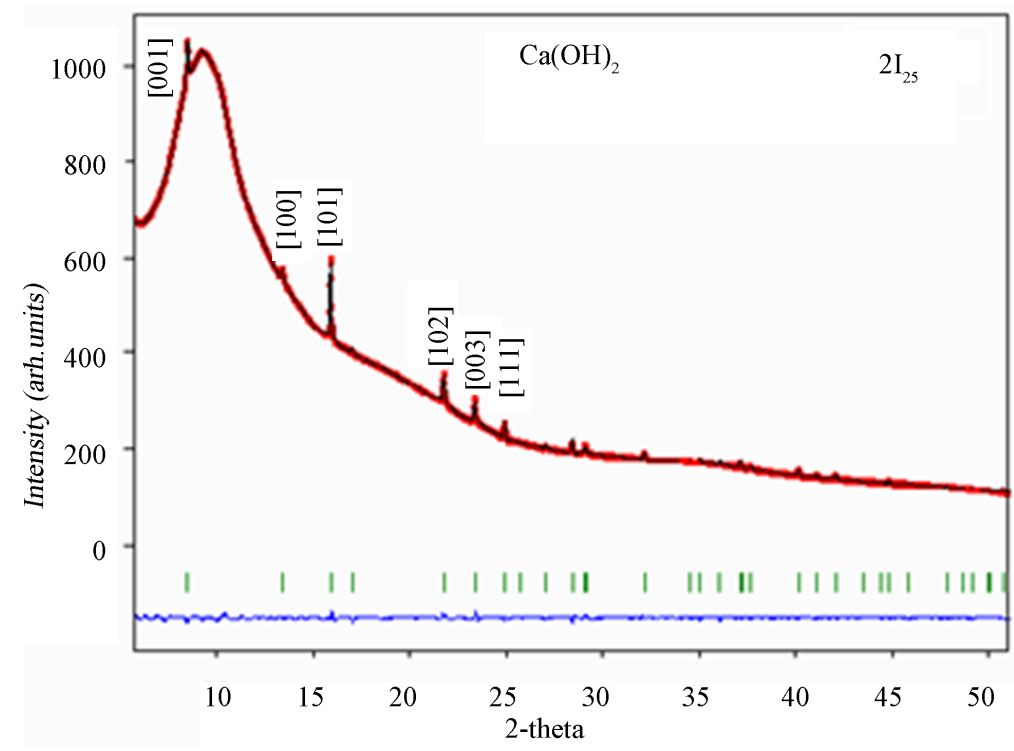

Figure 4. Diffraction pattern of $2 \mathrm{I}_{25}$ sample by SR-X ray technique at $\lambda=$ $0.7277 \AA$. The most intense peaks were indexed. 
Table 1. Cell parameters and atomic coordinates, interatomic distances and bond angles of $\mathrm{Ca}(\mathrm{OH})_{2}$ particles in hydro-alcoholic suspension, (samples from different synthesis methods). We compared here the results considering a water residual content of $75 \%$. Calcium atomic coordinates occupied the special position $(0,0,0)$.

\begin{tabular}{|c|c|c|c|}
\hline & $\mathbf{1}_{75}$ & $2 \mathbf{I}_{75}$ & $2 \mathbf{I I}_{75}$ \\
\hline $\mathrm{a}=\mathrm{b}(\AA)$ & $3.599(1)$ & $3.5940(6)$ & $3.5939(6)$ \\
\hline c $(\AA)$ & 4.917 (3) & $4.910(2)$ & $4.911(2)$ \\
\hline Volume & $55.16(4)$ & $54.93(2)$ & $54.94(2)$ \\
\hline \multicolumn{4}{|l|}{$\mathbf{O}$} \\
\hline$x(\AA)$ & 0.33333 & 0.33333 & 0.33333 \\
\hline $\mathrm{y}(\AA)$ & 0.66667 & 0.66667 & 0.66667 \\
\hline $\mathrm{z}(\AA)$ & $0.73(5)$ & $0.73(3)$ & $0.72(4)$ \\
\hline \multicolumn{4}{|l|}{$\mathbf{H}$} \\
\hline$x(\AA)$ & $0.43(6)$ & $0.44(3)$ & $0.44(3)$ \\
\hline $\mathrm{y}(\AA)$ & $0.9(1)$ & $0.87(5)$ & $0.88(6)$ \\
\hline $\mathrm{z}(\AA)$ & $0.36(5)$ & $0.37(3)$ & $0.37(4)$ \\
\hline Ca-O distance ( $\AA$ ) & $2.5(1)$ & $2.46(8)$ & $2.5(1)$ \\
\hline O-H distance (Å) & $1.9(3)$ & $1.9(2)$ & $1.8(3)$ \\
\hline O-Ca-O angle $\left(^{\circ}\right)$ & $94(4)$ & $94(3)$ & $92(4)$ \\
\hline H-Ô-H angle $\left(^{\circ}\right)$ & $33(1)$ & $34(9)$ & $36(1)$ \\
\hline
\end{tabular}

Table 2. Cell parameters, atomic coordinates, interatomic distances and bond angles of $\mathrm{Ca}(\mathrm{OH})_{2}$ particles of 2I and 2II series in relation to different contents of water in hydro-alcoholic suspension.

\begin{tabular}{|c|c|c|c|c|c|c|}
\hline & $2 I_{100}$ & $2 \mathbf{I}_{75}$ & $2 \mathbf{I}_{25}$ & $2 \mathrm{II}_{75}$ & $2 \mathrm{II}_{50}$ & $2 \mathrm{II}_{25}$ \\
\hline $\mathrm{a}=\mathrm{b}(\AA)$ & $3.596(1)$ & $3.5940(6)$ & $3.5898(7)$ & $3.5939(6)$ & $3.5954(8)$ & $3.5952(8)$ \\
\hline $\mathrm{b}$ & $3.596(1)$ & $3.5940(6)$ & $3.5898(7)$ & $3.5939(6)$ & $3.5954(8)$ & 3.5952 (8) \\
\hline c & $4.913(3)$ & $4.910(2)$ & $4.906(2)$ & $4.911(2)$ & $4.914(2)$ & 4.915 (2) \\
\hline Volume & $55.01(5)$ & $54.93(2)$ & $54.76(2)$ & $54.94(2)$ & $55.02(3)$ & $55.02(3)$ \\
\hline \multicolumn{7}{|l|}{$\mathbf{O}$} \\
\hline $\mathrm{x}$ & 0.33333 & 0.33333 & 0.33333 & 0.33333 & 0.33333 & 0.33333 \\
\hline $\mathrm{y}$ & 0.66667 & 0.66667 & 0.66667 & 0.66667 & 0.66667 & 0.66667 \\
\hline $\mathrm{z}$ & $0.8(1)$ & $0.73(3)$ & $0.71(4)$ & $0.72(4)$ & $0.73(4)$ & $0.74(4)$ \\
\hline \multicolumn{7}{|l|}{$\mathbf{H}$} \\
\hline $\mathrm{x}$ & $0.5(1)$ & $0.44(3)$ & $0.43(3)$ & $0.44(3)$ & $0.44(4)$ & $0.44(5)$ \\
\hline $\mathrm{y}$ & $0.7(2)$ & $0.87(5)$ & $0.85(6)$ & $0.88(6)$ & $0.883(8)$ & $0.88(7)$ \\
\hline $\mathrm{z}$ & $0.4(1)$ & $0.37(3)$ & $0.37(3)$ & $0.37(4)$ & $0.37(5)$ & $0.38(4)$ \\
\hline$\chi^{2}$ & 0.01 & 0.02 & 0.02 & 0.01 & 0.008 & 0.007 \\
\hline Ca-O distance ( $\AA$ ) & $2.4(3)$ & $2.46(8)$ & $2.4(1)$ & $2.5(1)$ & $2.5(1)$ & $2.4(1)$ \\
\hline O-H distance ( $\AA$ ) & $1.9(8)$ & $1.9(2)$ & $1.7(3)$ & $1.8(3)$ & $1.9(3)$ & $1.9(3)$ \\
\hline O-Ca-O angle $\left({ }^{\circ}\right)$ & 99 (1) & $94(3)$ & $98(3)$ & $92(4)$ & $94(3)$ & $95(3)$ \\
\hline $\mathrm{H}-\mathrm{O}-\mathrm{H}$ angle $\left({ }^{\circ}\right)$ & $32(4)$ & $34(9)$ & $38(1)$ & $36(1)$ & $35(1)$ & $35(1)$ \\
\hline
\end{tabular}

Analyzing the results obtained from 2I series, we founded that increasing the water residual content in the hydro-alcoholic suspension, $\mathrm{Ca}(\mathrm{OH})_{2}$ cell parameters tend to increase, probably due to the higher water ability to enter in the crystalline structure with respect to 2-propanol. Decreasing water content, the volume of unitary cell decreased smoothly too. The results obtained considering O-H distances and corresponding angles, tended to indicate a little distortion of the cell arising when water diminishes.

As concerns 2II series, changing the water residual content, we have not observed differences in terms of cell 
parameters and atomic coordinates. This result could be related to the presence of surfactant not well removed from the suspension itself; as a matter of fact, the residual surfactant could surround the $\mathrm{Ca}(\mathrm{OH})_{2}$ particles limiting the hydration of the $\mathrm{Ca}(\mathrm{OH})_{2}$ structure.

Below, we reported the study on preferred crystallographic orientation of $\mathrm{Ca}(\mathrm{OH})_{2}$ nanoparticles, by using March model [24]. In Figure 5 we reported, as an example, the diffraction spectrum referred to (001) $\mathrm{Ca}(\mathrm{OH})_{2}$ peak for 2I series; these patterns were analyzed without March model and with random orientation.

Comparing all the images in Figure 5, it was possible to note that the intensity discrepancy between the experimental and the refined data tended to increase for higher values of 2-propanol content (lower water residual content); this intensity discrepancy was not particularly marked in 2I sample, when alcohol was absent. Initially, $P_{h}$ value (as referred in formula 1) were included after the preliminary refinement starting with random orientation of the crystallites (without preferred orientation correction).

Considering the observed intensity discrepancies, we then checked several preferred orientations [34]: we observed a good correspondence between experimental and refined data only taking into account the preferred orientation along z-direction. These results were reported in Figure 6, where $(001) \mathrm{Ca}(\mathrm{OH})_{2}$ peak for 2 I series after the correction and with a preferred orientation along z-axis, was shown. Same results were observed on the $(001) \mathrm{Ca}(\mathrm{OH})_{2}$ peak of 2 II series.

Applying the March model we also obtained the $G_{1}$ parameters, refined for each sample (see Table 3).
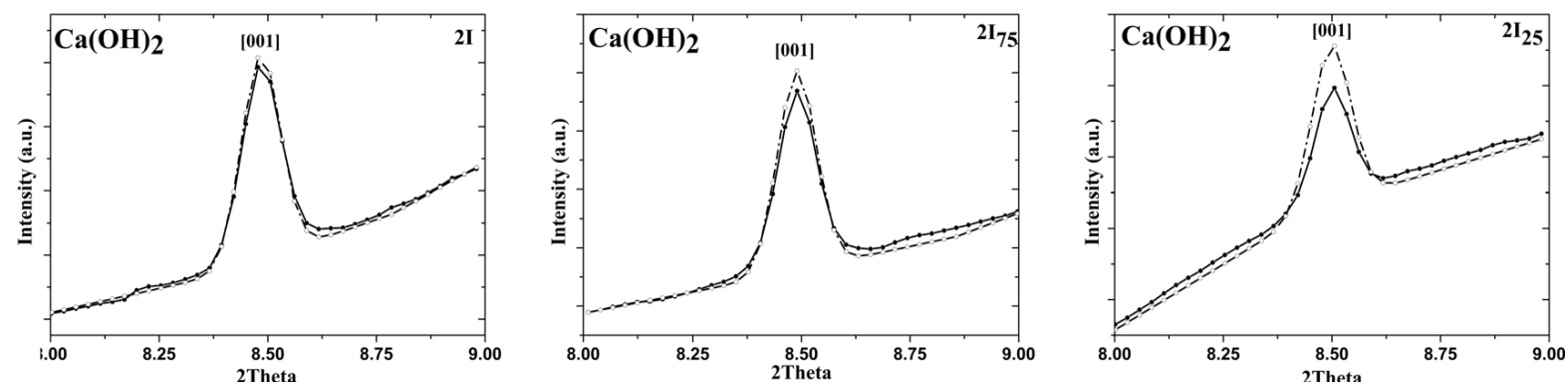

Figure 5. Rietveld analysis without March model (random orientation), on the (001) $\mathrm{Ca}(\mathrm{OH})_{2}$ peak: $2 \mathrm{I}, 2 \mathrm{I}_{75}$, and $2 \mathrm{I}_{25}$ sample. Note that experimental data were reported with straight line, while the refined data with dot line.
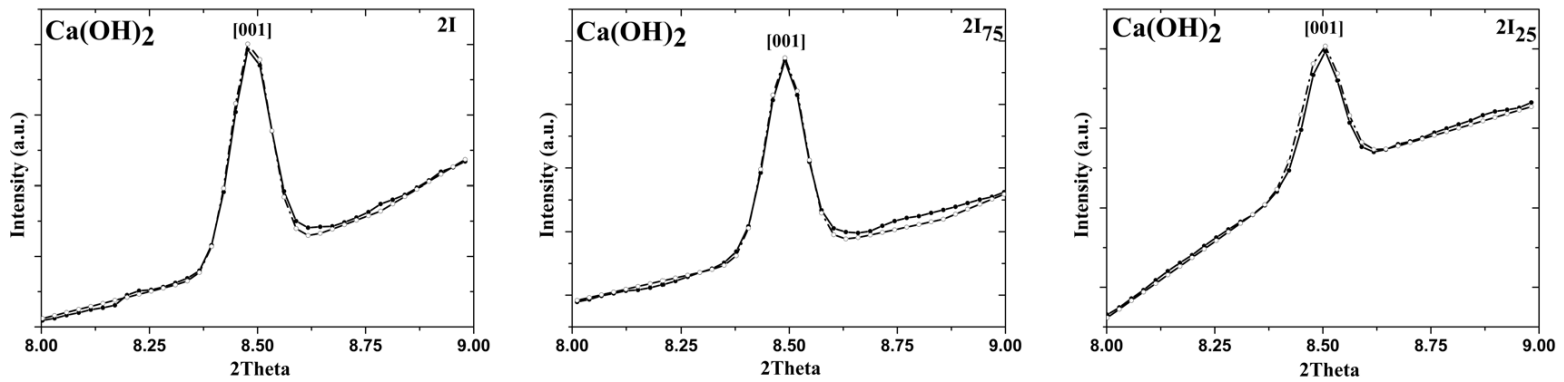

Figure 6. Rietveld analysis with March model on the [001] $\mathrm{Ca}(\mathrm{OH})_{2}$ peak: $2 \mathrm{I}_{2} 2 \mathrm{I}_{75}$, and $2 \mathrm{I}_{25}$ sample. Note that experimental data were reported with straight line, while the refined data with dot line.

Table 3. $\mathrm{G}_{1}$ values obtained for the considered samples.

\begin{tabular}{ccc}
\hline Sample denomination & $\mathbf{G}_{1}$ value \\
\hline $\mathbf{1}_{75}$ & $1.2(0.1)$ \\
$\mathbf{2} \mathbf{I}_{100}$ & $1.2(0.1)$ \\
$2 \mathbf{I}_{75}$ & $1.13(0.06)$ \\
$2 \mathbf{I}_{25}$ & $1.25(0.09)$ \\
$2 \mathbf{I I}_{75}$ & $1.17(0.07)$ \\
$2 \mathbf{I I}_{50}$ & $1.16(0.09)$ \\
$2 \mathbf{I I}_{25}$ & $1.15(0.08)$ \\
\hline
\end{tabular}




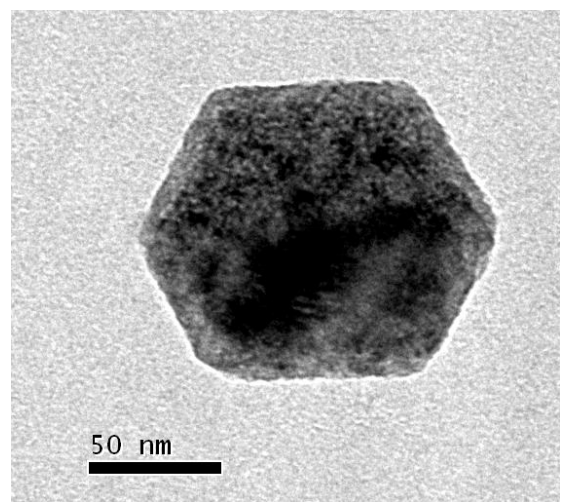

(a)

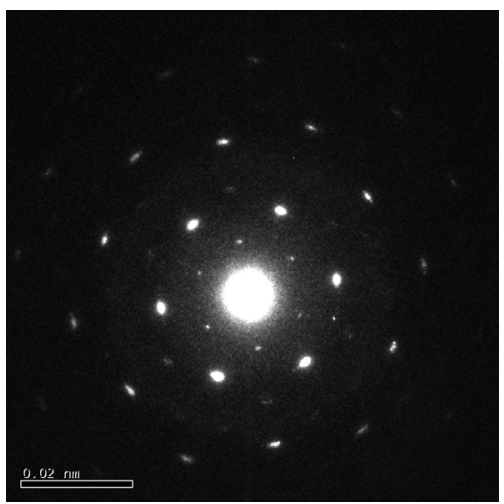

(b)

Figure 7. (a) TEM image of a hexagonal $\mathrm{Ca}(\mathrm{OH})_{2}$ nanoparticle obtained by adding the surfactant agent in the initial solutions; (b) the corresponding electron diffraction image (ED).

If $G_{1}>1$ the particles had "platy habit", if $G_{1}=1$ the particles were isotropic and $G_{1}<1$ they presented a "needle habit". Since the value of $G_{1}$ was higher than 1 , in the error range, for all the series it was possible to conclude that all the considered samples were characterized by a "platy habit" [29]. Finally, calculating for each reflection the coherent domain size, we founded average values of: 165.4 (2) nm (1 sample), 127.9 (1) nm (2I sample), and 142.7 (2) nm (2II sample), showing submicrocrystalline phases. These results, compared to the particles dimension observed by TEM, could indicate that a large amount of $\mathrm{Ca}(\mathrm{OH})_{2}$ particles were single crystals. This assertion moreover, was coherent with our previous results obtained by electron diffraction measurements, carried out on analogous nanolime hydro-alcoholic suspension [22], and reported in Figure 7.

\section{Conclusion}

Nanolime was today successfully employed in form of hydro-alcoholic suspensions in Cultural Heritage conservation; their application was more effective when the particles were small and well dispersed. The present work was then focused on a new synthesis of $\mathrm{Ca}(\mathrm{OH})_{2}$ nanoparticles, in hydro-alcoholic suspensions, by using a surfactant agent to obtain very small particles easily and reducing drastically the time needful for preparation. We studied $\mathrm{Ca}(\mathrm{OH})_{2}$ nanoparticles structure by SR-X ray diffraction measurements directly in suspension changing the surfactant content and the water/alcohol ratio in the suspension itself. The synthesized nanolime appeared hexagonally plated and regularly shaped, with side dimension ranging from $300 \mathrm{~nm}$ to $20 \mathrm{~nm}$ or less. From SR-X ray measurements, we founded that only pure and crystalline particles of calcium hydroxide nucleated and grown during the synthesis procedure maintain stable in suspension; moreover, we founded that the addition of surfactant during the synthesis tended to reduce the cell parameters of $\mathrm{Ca}(\mathrm{OH})_{2}$ particles in suspension. Finally, we founded that the $\mathrm{Ca}(\mathrm{OH})_{2}$ crystallites were characterized by a platy-like habit, with a preferred orientation along z-axis; this effect was more evident increasing 2-propanol content. The study of apparent size showed that a large amount of $\mathrm{Ca}(\mathrm{OH})_{2}$ particles were single crystals. The very easy and time saving protocol to produce well dispersed and reactive $\mathrm{Ca}(\mathrm{OH})_{2}$ nanoparticles, proposed in this work, was very promising for future applications in the conservation science and in Cultural Heritage consolidation as well in architectural domains.

\section{Acknowledgements}

We would like to thank to Dr. Thomas Hansen for the fruitful discussion about March model. The experimental assistance of Dr. D'Acapito is gratefully acknowledged. We would also like to thank to Professor Roberto Volpe for his helpful comments during the investigation.

\section{References}

[1] Boynton, R.S. (1980) Chemistry and Technology of Lime and Limestone. John Wiley \& Sons, New York.

[2] Adroer, M., Valero, F., Poch, M. and Sola, C. (1994) A New Procedure for Water Decarbonation Process Control. In- 
dustrial \& Engineering Chemistry Research, 33, 1501.

[3] Yan, K., Chin, T., Liang, D.T., Laursen, K., Ong, W.Y., Yao, K. and Tay, J.H. (2003) Kinetic Study of Hydrated Lime Reaction with HC. Environmental Science \& Technology, 37, 2556. http://dx.doi.org/10.1021/es020902v

[4] Foreman, P.C. and Barnes, I.E. (1990) A Review of Calcium Hydroxide. International Endodontic Journal, 23, 283297. http://dx.doi.org/10.1111/j.1365-2591.1990.tb00108.x

[5] Murray, P.E., Hafez, A.A., Smith, A.J. and Cox, C.F. (2002) Hierarchy of Pulp Capping and Repair Activities Responsible for Dentin Bridge Formation. American Journal of Dentistry, 15, 236.

[6] Ashurst, N. (1994) Cleaning Historic Buildings. London.

[7] Ashurst, J. and Dimes, F.G. (1998), Conservation of Building and Decorative Stone. Butterworth-Heinemann Series in Conservation and Museology. Butterworth-Heinemann, Oxford and Woburn.

[8] Elert, K., Rodriguez-Navarro, C., Sebastian Pardo, E., Hansen, E. and Cazalla, O. (2002) Lime Mortars for the Conservation of Historic Buildings. Studies in Conservation, 47, 62-75.

[9] Giorgi, R., et al. (2000) A New Method for Consolidating Wall Paintings Based on Dispersion of Lime in Alcohol. Studies in Conservation, 45, 154-161.

[10] Baglioni, P. and Giorgi, R. (2006) Soft and Hard Nanomaterials for Restoration and Conservation of Cultural Heritage. Soft Matter, 2, 293-303. http://dx.doi.org/10.1039/b516442g

[11] López-Arce, P., et al. (2010) Influence of Porosity and Relative Humidity in the Consolidation of Dolostone with Calcium Hydroxide Nanoparticles: Assessment of Consolidation Effectiveness with Non Destructive Techniques. Materials Characterization, 61, 168-184. http://dx.doi.org/10.1016/j.matchar.2009.11.007

[12] Slížková, Z., et al. (2010) Consolidation of Porous Limestone with Suspensions of Calcium Hydroxide Nano-Particles in Alcohols. In: Litomyšl, Eds., Stonecore-“Recent Progress in the Consolidation of Calcareous Materials”, Czech Republic.

[13] Daniele, V. and Taglieri, G. (2010) Nanolime Suspensions Applied on Natural Lithotypes: The Influence of Concentration and Residual Water Content on Carbonatation Process and on Treatment Effectiveness. Journal of Cultural Heritage, 11, 102-106. http://dx.doi.org/10.1016/j.culher.2009.04.001

[14] Dei, L. and Salvadori, B. (2006) Nanotechnology in Cultural Heritage Conservation: Nanometric Slaked Lime Saves Architectonic and Artistic Surfaces from Decay. Journal of Cultural Heritage, 7, 110-115. http://dx.doi.org/10.1016/j.culher.2006.02.001

[15] Pianski, J., Brümmer, K. and Ziegenbalg, G. (2010) Nano-Particles for Stone Conservation-State of the Art, Characteristics and Recent Developments. In: Litomyšl, Eds., Stonecore-"Recent Progress in the Consolidation of Calcareous Materials", Czech Republic.

[16] Daniele, V. and Taglieri, G. (2011) Ca(OH) $)_{2}$ Nanoparticles Characterization: Microscopic Investigation of Their Application on Natural Stones. In: Mammoli, A.A., Brebbia, C.A. and Klemm, A., Eds., Materials Characterisation VComputational Methods and Experiments, WIT Press, UK, 55-66. http://dx.doi.org/10.2495/MC110051

[17] Daniele, V., Taglieri, G. and Quaresima, R. (2008) The Nanolimes in Cultural Heritage Conservation: Characterisation and Analysis of the Carbonatation Process. Journal of Cultural Heritage, 9, 294-301. http://dx.doi.org/10.1016/j.culher.2007.10.007

[18] Hansen, E., et al. (2003) A Review of Selected Inorganic Consolidants and Protective Treatments for Porous Calcareous Materials. Studies in Conservation, 48, 13-25. http://dx.doi.org/10.1179/sic.2003.48.Supplement-1.13

[19] Salvadori, B. and Dei, L. (2001) Synthesis of $\mathrm{Ca}(\mathrm{OH})_{2}$ Nanoparticles from Diols. Langmuir, 17, 2371-2374. http://dx.doi.org/10.1021/la0015967

[20] Liu, T., et al. (2010) Synthesis and Characterization of Calcium Hydroxide Nanoparticles by Hydrogen Plasma-Metal Reaction Method. Materials Letters, 64, 2575-2577. http://dx.doi.org/10.1016/j.matlet.2010.08.050

[21] Roy, A. and Bhattacharya, J. (2010) Synthesis of $\mathrm{Ca}(\mathrm{OH})_{2}$ Nanoparticles by Wet Chemical Method. Micro \& Nano Letters, 5, 131-134. http://dx.doi.org/10.1049/mnl.2010.0020

[22] Daniele, V. and Taglieri, G. (2012) Synthesis of $\mathrm{Ca}(\mathrm{OH})_{2}$ Nanoparticles with the Addition of Triton X-100. Protective treatments on Natural Stones: Preliminary Results. Journal of Cultural Heritage, 13, 40-46. http://dx.doi.org/10.1016/j.culher.2011.05.007

[23] Daniele, V., Taglieri, G., Gregori, A. and Volpe, R. (2011) New Nano-Cementing Materials. In: 2nd Workshop ACI Italy Chapter "The New Boundaries of Structural Concrete”, 227-234.

[24] Dollase, W.A. (1986) Correction of Intensities for Preferred Orientation in Powder Diffractometry: Application of the March Model. Journal of Applied Crystallography, 19, 267-272. http://dx.doi.org/10.1107/S0021889886089458

[25] Taglieri, G., Daniele, V., Mondelli, C., Pusceddu, E. and Trapananti, A. (2013) Synthesis and X-Ray Diffraction Ana- 
lyses of Calcium Hydroxide Nanoparticles in Aqueous Suspension. Advances in Materials Physics and Chemistry, $\mathbf{3}$, 108-112. http://dx.doi.org/10.4236/ampc.2013.31A013

[26] Hammersley, A.P., Svensson, S.O., Hanfland, M., Fitch, A.N. and Häusermann, D. (1996) Two-Dimensional Detector Software: From Real Detector to Idealised Image or Two-Theta Scan. High Pressure Research, 14, 235-248. http://dx.doi.org/10.1080/08957959608201408

[27] Rodriguez-Carvajal, J. (1993) Fullprof Program. Physica B, 55, 192.

[28] Desgranges, L., et al. (1993) Hydrogen Thermal Motion in Calcium Hydroxide: $\mathrm{Ca}(\mathrm{OH})_{2}$. Acta Crystallographica B, 49, 812-817. http://dx.doi.org/10.1107/S0108768193003556

[29] Klug, H.P. and Alexander, L.E. (1974) X-Ray Diffraction Procedures. 2nd Edition, Wiley, New York, 302-303.

[30] Dhanam, M., et al. (2009) Analysis of ZnS Nanoparticles Prepared by Surfactant Micelle-Template Inducing Reaction. Chalcogenide Letters, 12, 713-722.

[31] Thompson, P., Cox, D.E. and Hastings, J.B. (1987) Rietveld Refinement of Debye-Scherrer Synchrotron X-Ray Data from $\mathrm{Al}_{2} \mathrm{O}_{3}$. Journal of Applied Crystallography, 20, 79. http://dx.doi.org/10.1107/S0021889887087090

[32] Rasberry, S., et al. (1989) National Institute of Standards and Technology SRM Certificates, Standard Reference Materials 660. Report, National Institute of Standards and Technology.

[33] Roisnel, T. and Rodriguez-Carvajal, J. (2000) WinPLOTR: A Windows Tool for Powder Diffraction Patterns Analysis. Materials Science Forum, Proceedings of the Seventh European Powder Diffraction Conference, 118-123.

[34] Rodríguez-Carvajal, J. (2001) An Introduction to the Program FullProf. 